\title{
Determinação da composição química e potencial de polpação da madeira Pterogyne nitens Tul.
}

\author{
Determination of the chemical composition and the wood pulping potential of \\ Pterogyne nitens Tul.
}

\section{Allana Katiussya Silva Pereira' ${ }^{\mathrm{I}}$, Dalton Longue Junior ${ }^{\mathrm{II}}$, Caio da Silva Mafra Neto ${ }^{\mathrm{I}}$, Jorge Luiz Colodette ${ }^{\mathrm{III}}$, Fernando José Borges Gomes ${ }^{\mathrm{IV}}$}

\section{Resumo}

A grande dependência por madeiras das espécies dos gêneros Eucalyptus e Pinus associada à busca por produtos de diferentes qualidades impulsionam estudos acerca de madeiras alternativas para fins industriais, principalmente de espécies do bioma Caatinga, pouco estudado para fins florestais. O objetivo deste estudo foi caracterizar quimicamente a madeira da espécie Pterogyne nitens assim como analisar seu potencial para produção de polpa celulósica. Foram colhidas três árvores representativas de 9 anos, em um plantio experimental localizado na Universidade Estadual do Sudoeste da Bahia - Campus Vitória da Conquista, e amostradas cinco seções do fuste entre as posições 0, 25, 50, 75 e 100\% da altura comercial. Os toretes foram transformados em cavacos e homogeneizados formando uma amostra composta representativa para a análise de densidade básica e composição química completa, bem como para a realização da polpação Kraft (cinco cozimentos utilizando diferentes cargas de álcali efetivo objetivando um Número Kappa 18). A densidade básica da madeira Pterogyne nitens foi de $641 \mathrm{~kg} / \mathrm{m}^{3}$, sua composição química apresentou $41,9 \%$ de celulose, $24,7 \%$ de hemiceluloses, $26,5 \%$ de lignina, $7,3 \%$ de extrativos e $0,5 \%$ de cinzas. O rendimento do cozimento para Número Kappa 18 foi $46,4 \%$ e viscosidade $1075 \mathrm{dm}^{3} / \mathrm{kg}$. A espécie não se apresentou como uma alternativa interessante para a produção de polpa celulósica (baixo teor de celulose e rendimento depurado), mas bastante promissora para aplicação na área de energia da madeira.

Palavras-chave: Celulose; Bioma Caatinga; Qualidade da madeira; Processo Kraft

\begin{abstract}
The strong dependence on wood from species like Eucalyptus and Pinus genus, associated to the search for products of different qualities, led to studies about alternative wood for industrial use, mainly about species from the Caatinga biome and which is understudied for forest purposes. The aim of this study was to characterize chemically the wood from the species Pterogyne nitens and analyze its potential for pulp production. Three representative trees of 9 years old were harvested in an experimental plantation located in the southwest of Bahia state, the University of Vitória da Conquista Campus, and sampled five short logs at $0,25,50,75$ and $100 \%$ of the commercial height. Logs were transformed in chips and homogenized to obtain a representative composed sample for the total chemical analysis (cellulose, hemicelluloses, lignin, extractives and ashes content) and Kraft pulping (five cooking using different effective alkali loads to establish Kappa number 18). Pterogyne nitens wood basic density was $641 \mathrm{~kg} / \mathrm{m}^{3}$, its chemical composition showed contents of cellulose (41.9\%), hemicelluloses (24.7\%), lignin (26.5\%), extractives (7.3\%) and ashes (0.5\%). Pulping yield at Kappa number 18 was $46.4 \%$ and viscosity $1075 \mathrm{dm}^{3} / \mathrm{kg}$. The species did not suggest as an interesting alternative for pulp production (low cellulose content and screened yield), but very promising for application in the biomass energy area.
\end{abstract}

Keywords: Cellulose; Caatinga biome; Wood quality; Kraft process

Engenheiro(a) Florestal, Colegiado de Engenharia Florestal, Universidade Estadual do Sudoeste da Bahia, Estrada do Bem Querer, Km 4, CEP 45083-900, Vitória da Conquista (BA), Brasil. allana.florestal@gmail.com (ORCID: 0000-0003-0425-4668) / caio_mafraflorestal@yahoo.com.br (ORCID: 0000-0003-2108-8024)

Engenheiro Florestal, Dr., Professor do Colegiado de Engenharia Florestal, Universidade Estadual do Sudoeste da Bahia, Estrada do Bem Querer, Km 4, CEP 45083-900, Vitória da Conquista (BA), Brasil. dalton@uesb.edu.br (ORCID: 0000-0002-5149-3074)

III Engenheiro Florestal, Dr., Professor do Departamento de Engenharia Florestal, Universidade Federal de Viçosa, Av. P. H. Rolfs, s/n, CEP 36570-000, Viçosa (MG), Brasil. colodett@ufv.br (ORCID: 0000-0001-6790-6104)

IV Engenheiro Florestal, Dr., Professor do Departamento de Produtos Florestais, Universidade Federal Rural do Rio de Janeiro, Rodovia BR-465, Km 7, CEP 23897-000, Seropédica (RJ), Brasil. fjbgomes@yahoo.com.br (ORCID: 0000-0003-0363-4888) 


\section{Introdução}

Nos últimos anos, o setor florestal brasileiro vem atravessando um período de intenso desenvolvimento tecnológico. O avanço tecnológico ocorrido nas florestas e nas indústrias de transformação da madeira, aliado ao crescimento populacional e à alta demanda por produtos e subprodutos de origem florestal, foram os principais fatores que impulsionaram essa evolução. Tudo isso tem levado ao aumento da produção de madeira e seus derivados, material mais produzido e requisitado por abastecer principalmente as indústrias de celulose e papel, polpa solúvel, energia (lenha e carvão vegetal), produtos sólidos de madeira (madeira serrada e painéis de madeira), entre outros.

Este intenso desenvolvimento do setor deve ser acompanhado pelo aumento das áreas cobertas por florestas plantadas, que no ano de 2005 correspondia a aproximadamente 5,6 milhões de hectares e, em 2016, 7,84 milhões de hectares (IBÁ, 2017), apresentando um crescimento satisfatório, mas pouco expressivo para um país de dimensões continentais como o Brasil.

As espécies dos gêneros Eucalyptus e Pinus ocupam a maior parte dessa área total devido ao fato de terem sido as mais estudadas e adaptadas para fins industriais (IBÁ, 2017; REIS et al., 2015). Suas fibras e produtos são comercializados em todo o mundo, já que suas características tecnológicas foram bem determinadas e selecionadas pelo mercado, principalmente para aplicação no setor de celulose e papel. Entretanto, apesar de existirem centenas de espécies desses gêneros já conhecidas pelo homem, poucas são utilizadas em plantios comercias, estabelecidos em pequenas ou grandes áreas, o que não é ambientalmente muito recomendado. O questionamento desta prática ocorre devido à baixa diversidade florestal que pode ocorrer nesses locais, proveniente de aspectos como a redução da diversidade do banco de sementes (NÓBREGA et al., 2009), visto que o mesmo pode ser considerado um mecanismo fundamental ao estabelecimento de novas espécies comerciais (GONÇALVES et al., 2008).

Devido ao estreitamento da diversidade florestal gerado a partir da utilização de poucas espécies dos gêneros Eucalyptus e Pinus, associado à grande dependência dessas espécies e ao aumento da procura por madeiras alternativas para o setor industrial, se torna válido um estudo detalhado sobre diferentes espécies ou gêneros, como Pterogyne nitens. Pertencente à família Fabaceae, essa espécie se torna interessante a ser analisada por apresentar boa ocorrência em muitos estados do Brasil (Alagoas, Bahia, Espírito Santo, Mato Grosso, Mato Grosso do Sul, Minas Gerais, Paraíba, Paraná, Pernambuco, Rio Grande do Sul, São Paulo e Sergipe) (LORENZI, 1992), e por se destacar na Caatinga, bioma carente de espécies com potencial de exploração florestal. Também não existem muitas pesquisas divulgadas sobre suas características tecnológicas e esta falta de informação pode estar implicando em sua reduzida ou até inexistente utilização no mercado (SILVA et al, 2009).

Em plantios puros, a espécie apresenta um crescimento em volume médio estimado de $0,0451 \mathrm{~m}^{3}$ por árvore aos 6 anos, plantadas em espaçamento $3 \times 3 \mathrm{~m}$, estimando uma produtividade de $6,01 \mathrm{~m}^{3} /$ ha/ano (FRAGA et al., 2014).

A madeira, de um modo geral, apresenta uma série de características tecnológicas que influenciam nas propriedades dos produtos e variam entre as espécies. Dentre essas, destacamse as características químicas por apresentarem alta relação com as demais características (anatômicas, físicas e mecânicas), influenciando seu comportamento, bem como de seus derivados (ZIECH, 2008).

Assim, devido ao fato do Brasil possuir grande potencial para produção florestal e a Caatinga ter sido pouco estudada até o momento, aliado à necessidade de se buscar diferentes espécies para a exploração comercial, a espécie Pterogyne nitens aparece como uma possível alternativa para essa região. O objetivo desse estudo foi estudar detalhadamente a composição química e a densidade básica dessa espécie e avaliar o seu potencial de utilização como matériaprima na produção de polpa celulósica. 


\section{Material e método}

\section{Amostragem e coleta da madeira}

A amostragem e a coleta do material foram realizadas em um plantio experimental da espécie Pterogyne nitens localizado na Universidade Estadual do Sudoeste da Bahia - Campus Vitória da Conquista. A região apresenta precipitação pluviométrica variando de 700 a $1000 \mathrm{~mm}$ anuais, sendo os meses mais chuvosos de novembro a março. A temperatura média anual é de $21^{\circ} \mathrm{C}$. O solo da região é classificado como Latossolo Vermelho Amarelo (LVA) Distrófico, com textura média e de topografia suavemente ondulada a plana e boa drenagem. O plantio foi estabelecido há aproximadamente 9 anos com espaçamento de 3 x $3 \mathrm{~m}$ em uma altitude de aproximadamente $900 \mathrm{~m}$.

Foram colhidas três árvores representativas do povoamento em termos de altura $(10 \mathrm{~m}) \mathrm{e}$ DAP $(15 \mathrm{~cm})$, e retirado de cada uma cinco toretes entre as posições $0,25,50,75$ e $100 \%$ da altura comercial (diâmetro mínimo $=8 \mathrm{~cm}$ ). Os toretes foram transformados em cavacos por meio de um picador laboratorial dotado de duas peneiras classificadoras com aberturas de 39 x $39 \mathrm{~mm}$ e 6 × $6 \mathrm{~mm}$. Os cavacos foram reclassificados em peneira com abertura de 16 × $16 \mathrm{~mm}$, e, por fim, foi realizada uma classificação manual para eliminar pedaços de casca e cavacos com defeitos. Os cavacos foram misturados para formação de uma amostra composta homogênea.

\section{Determinação da composição química da madeira}

Para a determinação da composição química da madeira, uma amostra representativa dos cavacos foi transformada em serragem, utilizando moinho tipo Willey. A serragem foi classificada em peneiras 40 e 60 mesh, sendo a serragem a ser utilizada nas análises aquela que ficou retida na peneira de 60 mesh. A serragem foi acondicionada em sala com umidade relativa de $50 \% \pm 2 \%$ e temperatura de $23^{\circ} \mathrm{C} \pm 2^{\circ} \mathrm{C}$ e, em seguida, foi determinado seu teor absolutamente seco. A amostra foi acondicionada em recipiente hermeticamente fechado para manter sua umidade constante. $\mathrm{O}$ teor de hemiceluloses presente na madeira foi calculado pela soma dos grupos acetila, dos ácidos urônicos e dos açúcares (xilanas, arabinanas, galactanas e mananas). As análises químicas foram realizadas em triplicata e os respectivos procedimentos analíticos estão descritos na Tabela 1. Todos esses procedimentos foram realizados no Laboratório de Celulose e Papel da Universidade Federal de Viçosa.

Tabela 1 - Listagem dos procedimentos analíticos utilizados para estudo da madeira Pterogyne nitens.

Table 1 - List of the analytical procedures used to study the Pterogyne nitens wood.

\begin{tabular}{lc}
\multicolumn{1}{c}{ Parâmetros } & Procedimentos \\
\hline Preparo da amostra & TAPPI T257 om-02 \\
Teor de umidade & TAPPI T264 cm-07 \\
Teor de carboidratos & SCAN-CM 71:09 \\
Teor de ácidos urônicos & SCOTT, 1979 \\
Teor de grupos acetila & SOLAR et al., 1987 \\
Teor de lignina insolúvel em ácido & SCAN-CM 71:09 \\
Teor de lignina solúvel em ácido & TAPPI UM 250 \\
Relação siringila/guaiacila da lignina & LIN e DENCE, 1992 \\
Teor de extrativos totais & TAPPI T204 cm-97 (adaptado) \\
Teor de minerais & TAPPI T211 om-93 \\
\hline
\end{tabular}




\section{Polpação dos cavacos de madeira}

Aproximadamente $500 \mathrm{~g}$ de cavacos absolutamente secos foram submetidos a cinco cozimentos com diferentes cargas de álcali (com objetivo de obter uma polpa marrom de Número Kappa 18) em digestor batch tipo M\&K, com capacidade de 8 litros pelo processo Kraft. Esse digestor é equipado com um trocador de calor e bomba de circulação direta, sendo o tempo e a temperatura controlados por computador. Uma amostra de cavacos foi retirada para análise da densidade básica (ABNT NBR 11941/2003). Os parâmetros de cozimento estão descritos na Tabela 2.

\section{Tabela 2 - Condições do cozimento Kraft de cavacos da madeira Pterogyne nitens.}

Table 2 - Kraft cooking conditions of Pterogyne nitens wood chips.

\begin{tabular}{lc}
\hline \multicolumn{2}{c}{ Condições de cozimento Kraft } \\
\hline Tempo até temperatura - TTT (min) & 90 \\
Tempo à temperatura - TAT (min) & 90 \\
Temperatura de reação $\left({ }^{\circ} \mathbf{C}\right)$ & 170 \\
Álcali efetivo (\%) & $21,17,16$ e 14 \\
Sulfidez $(\%)$ & 32 \\
Relação licor/madeira $\left(\mathbf{m}^{\mathbf{3}} / \mathbf{t}\right)$ & $4: 1$ \\
\hline
\end{tabular}

Ao final do cozimento, o licor negro foi drenado do digestor e uma parte foi coletada e analisada quanto ao álcali efetivo residual (Tappi T $625 \mathrm{~cm}-85$ ) e $\mathrm{pH}$, enquanto os cavacos foram lavados de forma exaustiva com água corrente e a individualização das fibras foi feita em um hydrapulper com capacidade de 20 litros. A polpa foi depurada em um depurador laboratorial equipado com peneira de $0,2 \mathrm{~mm}$, desaguada a aproximadamente $30 \%$ de consistência e armazenada em sacos de polietileno. Foram determinados o Número Kappa (Tappi T $236 \mathrm{~cm}-85$ ), rendimento total (ou bruto) e depurado (Gravimétrico - Propriedade LCP/UFV), teor de rejeitos (Gravimétrico - Propriedade LCP/UFV) e viscosidade (Tappi T 230 om-94) da polpa marrom.

A análise de regressão foi realizada a partir dos dados dos cinco cozimentos, estabelecendose equações para correlacionar o álcali efetivo com parâmetros do processo e propriedades da polpa a Número Kappa 18.

\section{Análise estatística}

Os dados da composição química foram apresentados de forma descritiva, apresentando as médias dos resultados, de modo a caracterizar o material estudado. Uma comparação técnica foi realizada com outras espécies, tanto nativas como exóticas, baseada em literatura científica, a fim de facilitar a compreensão sobre o potencial para utilização da madeira Pterogyne nitens.

Com relação aos cozimentos dos cavacos, os valores de desempenho foram apresentados integralmente, e, a partir das correlações entre as variáveis de processo, foram estimadas as condições operacionais para obtenção e as estimativas da qualidade da polpa marrom em Número Kappa 18. 


\section{Resultados e discussão}

\section{Características físico-químicas da madeira Pterogyne nitens}

Os valores obtidos nas análises físico-químicas da madeira Pterogyne nitens estão apresentados na Tabela 3.

Tabela 3 - Resultados das análises físico-químicas da madeira Pterogyne nitens.

Table 3 - Results of physical-chemical analysis of Pterogyne nitens wood.

\begin{tabular}{lcc}
\hline \multicolumn{2}{c}{ Características } & Média \\
\hline Densidade básica $\left(\mathbf{k g} / \mathbf{m}^{\mathbf{3}}\right)$ & & 641 \\
\hline${ }^{*}$ Celulose (\%) & Xilanas & 41,9 \\
\hline & Galactanas & 14,3 \\
& Mananas & 0,97 \\
& Arabinanas & 0,88 \\
Hemicelulose (\%) & 0,93 \\
& Grupos Acetila & 4,00 \\
& Ácidos Urônicos & 3,68 \\
\hline Extrativos (\% em etanol/tolueno, 1:2) & Total & 24,7 \\
\hline Cinzas (\%) & & 7,28 \\
\hline \multirow{2}{*}{ Lignina (\%) } & & 0,45 \\
& Solúvel & 2,76 \\
& Insolúvel & 23,8 \\
& Total & 26,6 \\
\hline Relação S:G & Siringila, gmol & 1,58 \\
& Guaiacila, gmol & 0,73 \\
\hline & S:G & 2,17 \\
\hline
\end{tabular}

Em que: * teor de celulose igual ao de glicanas.

Ao se comparar a densidade dessa espécie $\left(641 \mathrm{~kg} / \mathrm{m}^{3}\right)$ da Caatinga com a de outras espécies nativas já estudadas para fins industriais, ela apresentou valor superior ao encontrado por Vidaurre (2010) para a espécie amazônica Schizolobium amazonicum $\left(275 \mathrm{~kg} / \mathrm{m}^{3}\right)$ e valor inferior ao valor encontrado por Gonçalves et al. (2010) para a espécie Mimosa caesalpiniaefolia (780 kg/ $\mathrm{m}^{3}$ ) do mesmo bioma; ao se comparar com um clone comercial de eucalipto, a madeira Pterogyne nitens apresentou valor de densidade básica maior que o valor encontrado por Mokfienski (2004) - Eucalyptus urophylla $\left(544 \mathrm{~kg} / \mathrm{m}^{3}\right)$.

A densidade básica da madeira é um parâmetro de grande importância nas indústrias de polpa celulósica por exercer influência antagônica no consumo específico de madeira $\left(\mathrm{m}^{3}\right.$ de madeira/tonelada de celulose) e nas propriedades e qualidade da polpa. O aumento da densidade básica da madeira permite uma maior quantidade de madeira dentro do digestor e consequentemente uma maior produção. Por outro lado, devido a essa maior densidade da madeira, existe uma maior dificuldade na individualização das fibras, demandando maior carga 
alcalina e tempo/temperatura para a deslignificação, o que acarreta em perda de rendimento. Dessa forma, a densidade da madeira para produção de polpa celulósica deve ser cuidadosamente analisada. Gomide et al. (2010) estudando clones de Eucalyptus sp. de empresas nacionais de polpa celulósica, encontraram uma faixa de densidade básica adequada variando de 429 a $555 \mathrm{~kg} / \mathrm{m}^{3}$. Diante desses números, a madeira Pterogyne nitens se destaca pela elevada densidade e deve ser também investigada quanto a sua composição química para ser considerada uma opção para produção de polpa.

Em relação à composição química da madeira, o conhecimento de sua natureza e das diferentes proporções dos seus componentes principais possibilita ao usuário o entendimento de seu comportamento como matéria-prima para os diversos fins industriais (SJÖSTRÖM, 1993), principalmente para a produção de polpa celulósica. A madeira Pterogyne nitens apresentou um teor de celulose de 41,9\%, maior em relação à espécie Mimosa caesalpiniaefolia (32,8\%) (GONÇALVES et al., 2010); entretanto, esse valor é menor que o encontrado para a espécie Schizolobium amazonicum (50,7\%) (VIDAURRE, 2010). Ao se comparar a madeira Pterogyne nitens com uma espécie comercial utilizada na produção de polpa celulósica no Brasil - Eucalyptus urophylla (50,9\%) (MOKFIENSKI, 2004) - o valor também se mostrou inferior, apresentando-se como uma opção também menos atrativa para este fim, já que o rendimento no processo de polpação está correlacionado positivamente com o teor de glicanas na madeira (FERREIRA et al., 2006).

O teor de hemiceluloses presente na madeira Pterogyne nitens apresentou um valor de 24,7\%. Quando comparada à espécie Eucalyptus urophylla estudada por Mokfienski (2004), percebese uma pequena diferença no teor de hemiceluloses entre elas, sendo a do Eucalyptus urophylla de 22,5\%. Em relação às espécies nativas, a Pterogyne nitens apresentou menor teor que a espécie Mimosa caesalpiniaefolia (33,2\%) e maior teor que a espécie Schizolobium amazonicum (14,9\%).

O teor de hemiceluloses está ligado tanto aos processos de polpação da madeira quanto à qualidade do produto. As hemiceluloses são muito hidrofílicas, devido às suas estruturas ramificadas e amorfas, o que facilita o inchamento das fibras através da absorção de água, promovendo a lubrificação interna e aumentando tanto a flexibilidade das fibras quanto a área de contato entre as mesmas (MANFREDI, 2013).

Dentre os açúcares que compõem as hemiceluloses de folhosas, destacam-se as xilanas, por serem encontradas em maiores quantidades em relação aos demais (SJÖSTRÖM, 1993). Isto pode ser confirmado, pois a madeira Pterogyne nitens, Eucalyptus urophylla e Schizolobium amazonicum apresentaram, respectivamente, teores de 14,3, 13,5 e 11,2\% de xilanas, maioritários dentre os açúcares componentes das hemiceluloses.

Para produção de polpa celulósica é importante estudar o teor das xilanas uma vez que, ligados às suas cadeias básicas, encontram-se grupos laterais que abrangem os ácidos urônicos e os grupos acetila. Além do consumo de álcali, os ácidos urônicos são geradores de ácidos hexenurônicos durante a polpação afetando negativamente o branqueamento da polpa (COSTA et al., 2001); a presença de grupos acetila nas xilanas constitui uma desvantagem tecnológica, pois, além de consumir álcali durante o cozimento Kraft, representa perda de rendimento, uma vez que são totalmente hidrolisados e solubilizados durante o cozimento (GOMIDE; FANTUZZI NETO, 2000). A espécie Pterogyne nitens apresentou teor de ácidos urônicos e de grupos acetila de, respectivamente, 3,7 e 4,0\%. Gomide et al. (2005), estudando espécies de eucaliptos utilizados por empresas no Brasil, verificaram um teor de ácidos urônicos variando de 3,2 a 4,7\% e um teor de grupos acetila variando de 2,6 a $3,1 \%$.

Sobre os demais açúcares (arabinana, manana e galactana) para a espécie Pterogyne nitens somaram $2,8 \%$ do peso da madeira seca, sendo próximo a soma para Eucalyptus urophylla $(2,1 \%)$ e maior que para a Schizolobium amazonicum (1,5\%). Percebe-se então que a madeira Pterogyne nitens apresentou maior teor de xilanas, menor teor de ácidos urônicos e maior teor de grupos acetilas quando comparada à espécie de Eucalyptus urophylla, mostrando-se interessante nesse aspecto para estudos de polpação da madeira. 
Em relação ao teor de lignina da madeira, o teor de lignina total é a soma dos teores da lignina Klason (insolúvel em ácido) e lignina solúvel em ácido. Para a espécie Pterogyne nitens, o teor de lignina Klason foi de $23,8 \%$ e o teor de lignina solúvel em ácido foi de $2,8 \%$ (Tabela 3), enquanto que, para as espécies Eucalyptus urophylla, Schizolobium amazonicum e Mimosa caesalpiniaefolia, o teor de lignina insolúvel variou de 23,6 a $24,6 \%$ e o teor de lignina solúvel variou de 1,8 a 3,0\% (GONÇALVES et al., 2010; MOKFIENSKI, 2004; VIDAURRE, 2010).

Folhosas que crescem em climas tropicais tendem a produzir normalmente altas concentrações de lignina total, como é o caso das madeiras de eucalipto plantadas no Brasil que possuem teores de lignina compreendidos entre 25 - 30\% (GOMIDE; COLODETTE, 2007). O teor de lignina total de Pterogyne nitens (26,5\%) está de acordo com os valores normais para as folhosas tropicais, sendo um valor similar ao do Eucalyptus urophylla $(26,6 \%)$ (MOKFIENSKI, 2004) e menor que da Schizolobium amazonicum (29,7\%) (VIDAURRE, 2010). Em seu estudo, Gonçalves et al. (2010) não informam o valor de lignina total da Mimosa caesalpiniaefolia, não sendo possível assim uma comparação exata, entretanto, pelo teor de lignina Klason apresentado (24,6\%), possivelmente seu teor de lignina total aproxima-se ao do valor encontrado para Pterogyne nitens.

Além da quantificação da lignina (lignina total), o estudo das estruturas químicas que a compõe também é importante, uma vez que elas afetam diretamente a reatividade e o rendimento dos processos de transformação da madeira em polpa celulósica. Assim, a relação S:G (siringila:guaiacila) da madeira Pterogyne nitens foi 2,17 (Tabela 3), isto é, a lignina dessa espécie apresenta um pouco mais de 2 unidades siringila para cada unidade guaiacila. Barbosa et al. (2008) relataram que, no processo de polpação, a velocidade de deslignificação da madeira é influenciada pala estrutura da lignina, sendo diretamente proporcional à relação $S / G$, uma vez que a estrutura siringila da lignina é mais reativa sendo, portanto, mais fácil de ser removida durante o processo de polpação Kraft, aumentando o rendimento. Gomes et al. (2008) ressaltam que a madeira desejável para produção de celulose Kraft deve apresentar baixo teor de lignina associado a uma alta relação $S / G$ da lignina.

Assim, o teor de lignina total da madeira Pterogyne nitens se encontra em conformidade com as demais madeiras comerciais brasileiras, sendo a relação $S: G$ da lignina ligeiramente baixa para sua aplicação no setor de polpa celulósica.

O teor de extrativos da madeira Pterogyne nitens foi de 7,3\%, valor maior que os teores dos extrativos relatados por Gomide et al. (2005) para várias espécies de eucaliptos utilizadas por empresas brasileiras de polpa celulósica (1,76 à 4,13\%). Madeiras com alto teor de extrativos apresentam menor rendimento em polpa e maior potencial para formação de depósitos (pitch) nas máquinas, levando a um aumento no custo de manutenção e perdas de qualidade no produto final (GOMIDE et al., 2005). Outro problema associado aos extrativos é o aumento no consumo de álcali e reações de saponificação, que demandam o uso de aditivos químicos no processo (antiespumantes). Por consequência, um elevado teor de extrativos na madeira contribui para o aumento do custo de produção (ANDO, 1999).

Por fim, a madeira Pterogyne nitens apresentou um teor de cinzas de 0,45\%. Fengel e Wegener (1984) relataram que o teor de cinzas para madeiras de clima tropical pode atingir até $5 \%$ do peso da madeira. Assim, pode-se considerar o teor de cinzas da Pterogyne nitens relativamente baixo. Considerando-se a produção de polpa celulósica, as cinzas podem gerar uma série de problemas no processo de polpação, dentre os quais incrustações e corrosões nas paredes e tubulações da seção de recuperação do licor residual (MATA, 2016). Uma vez que uma quantidade destes minerais adentra nas fábricas através da madeira (KIMO, 1986), é interessante escolher madeiras com um menor teor de cinzas.

\section{Simulação de cozimentos químicos (Kraft) utilizando cavacos de madeira Pterogyne nitens}

Os resultados do processo de polpação da madeira Pterogyne nitens estão apresentados na 
Tabela 4.

\section{Tabela 4 - Parâmetros do cozimento Kraft e características das polpas marrom e do licor negro residual.}

Table 4 - Kraft cooking parameters, unbleached pulp and residual black liquor characteristics.

\begin{tabular}{lcccccc}
\hline \multicolumn{1}{c}{ Cozimento } & $\mathbf{1}$ & \multicolumn{1}{c}{$\mathbf{2}$} & \multicolumn{1}{c}{$\mathbf{3}$} & \multicolumn{1}{c}{$\mathbf{4}$} & \multicolumn{1}{c}{$\mathbf{5}$} & $\mathbf{I}^{*}$ \\
\hline Número Kappa & 13,6 & 14,2 & 15,9 & 16,8 & 19,1 & $18,0^{*}$ \\
Álcali Efetivo (\%) & 21,0 & \multicolumn{1}{c}{19,0} & 17,0 & 17,5 & 16,0 & 16,4 \\
Viscosidade $\left(\mathbf{d m}^{\mathbf{3}} \mathbf{k g}\right)$ & 899 & 942 & 1024 & 1060 & 1113 & 1079 \\
Rendimento Depurado (\%) & 44,4 & \multicolumn{1}{c}{44,9} & 46,1 & 45,9 & 45,8 & 46,0 \\
Rejeito (\%) & 0,1 & 0,2 & 0,4 & 0,2 & 1,4 & - \\
Rendimento Total (\%) & 44,5 & 45,1 & 46,5 & 46,1 & 47,2 & - \\
Álcali Efetivo Residual (g/l) & 8,1 & 6,6 & 4,4 & 4,1 & 2,3 & - \\
pH do Licor Negro & 13,4 & 13,3 & 13,1 & 13,2 & 12,4 & - \\
\hline
\end{tabular}

Em que: I*Valores estimados para Número Kappa 18.

O Número Kappa da polpa marrom é um importante parâmetro para o processo de produção da polpa celulósica branqueada, pois indica a quantidade de lignina residual, importante para estabelecer a estratégia envolvida na fase de branqueamento, sendo comumente empregados valores próximos a 18 pela maioria das empresas.

Na Figura 1A é apresentada a relação entre a carga alcalina (expressa em álcali efetivo) e o Número Kappa após os cozimentos. Para Número Kappa 18 foi estimada uma carga de álcali efetivo de $16,4 \%$, valor esse considerado elevado quando comparado ao cozimento de madeiras comerciais, como eucalipto, quando utilizado o mesmo Número Kappa e sulfidez. Segundo Mokfienski (2004), o cozimento de madeiras de Eucalyptus urophylla consumiu 14,4\% de álcali efetivo para Número Kappa 18 (sulfidez 30\%).

Além do Número Kappa, outro importante valor a ser considerado no processo produtivo é o rendimento depurado, que indica, em valores percentuais, a quantidade de polpa celulósica produzida a partir de uma quantidade de madeira e, além de outros fatores, é influenciada pela carga alcalina. A Figura $1 \mathrm{~B}$ apresenta o comportamento do rendimento depurado às diferentes cargas de álcali nos cozimentos estudados. Segundo Gomide et al. (2005), a demanda de altas cargas de álcali constitui uma característica altamente desfavorável, uma vez que provoca perda de rendimento, degradação mais intensa das cadeias dos carboidratos, sobrecarga da caldeira de recuperação por elevação do teor de sólidos dissolvidos e consequente aumento do custo de produção. É neste ponto em que a Pterogyne nitens se apresenta como uma opção pouco viável para a produção de polpa celulósica. Com uma carga de álcali efetivo de 16,4\% (Kappa 18), foi estimado um rendimento depurado de $45,9 \%$, enquanto que para cavacos de Eucalyptus urophylla, utilizando-se uma carga de álcali efetivo de 14,4\% (Kappa 18), encontrou-se um rendimento depurado de 51,6\% (MOKFIENSKI, 2004). O teor de rejeitos para todos os cozimentos com Número Kappa inferior a 18 foi baixo $(<0,4 \%)$. Em outras palavras, além de ser necessário maior carga alcalina, a madeira Pterogyne nitens apresentou um rendimento depurado menor quando comparada a uma espécie utilizada pelas indústrias de polpa celulósica no Brasil. 


\section{Figura 1 - Relação entre (A) álcali efetivo x Número Kappa; (B) rendimento depurado $x$ álcali efetivo; $(\mathrm{C})$ viscosidade $\mathrm{x}$ álcali efetivo para polpa marrom de Pterogyne nitens.}

Figure 1 - Relationship between (A) effective alkali x Kappa number; (B) screened yield x effective alkali; (C) viscosity x effective alkali to unbleached pulp of Pterogyne nitens.

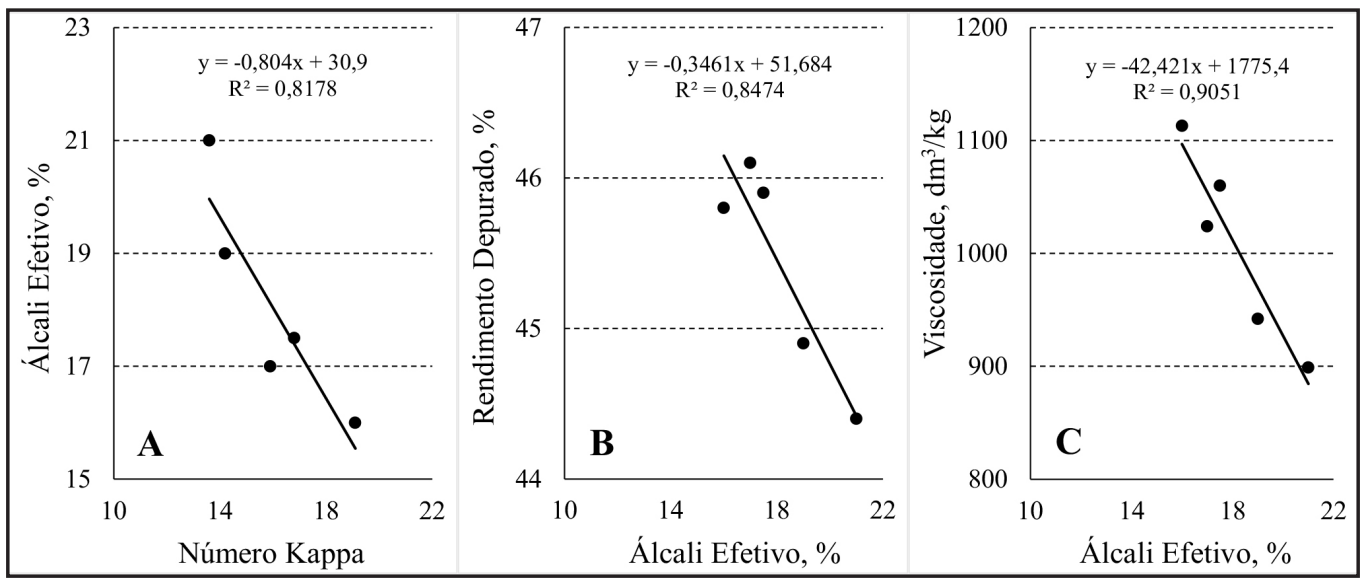

Fonte: Autores (2019)

Por fim, considerando a qualidade da polpa celulósica, outra característica de grande importância é a viscosidade, que expressa o grau de degradação das fibras de celulose ocorrida durante o processo de polpação. Na Figura 1C percebe-se um comportamento de decréscimo da viscosidade com o aumento da carga de álcali efetivo, que é explicado devido ao álcali não somente degradar a lignina, mas também as cadeias de celulose. A madeira Pterogyne nitens apresentou uma viscosidade estimada para Número Kappa $18 \mathrm{de} 1079 \mathrm{dm}^{3} / \mathrm{kg}$, enquanto que Mokfienski (2004) encontrou para Eucalyptus urophylla uma maior viscosidade (1365 $\left.\mathrm{dm}^{3} / \mathrm{kg}\right)$.

Além das características do produto, a análise dos parâmetros relacionados ao processo de cozimento também é importante, como o álcali efetivo residual. Normalmente, procura-se manter uma concentração de álcali residual dos licores na faixa de 5 a $12 \mathrm{~g} \mathrm{NaOH} / \mathrm{L}$ (GRACE et al., 1989). Foi observado em alguns cozimentos realizados que os valores de álcali efetivo residual ficaram abaixo da faixa recomendável, indicando a possibilidade de parte da lignina ter se precipitado novamente na superfície das fibras e que o aperfeiçoamento do cozimento (tempo e temperatura) para elevar o álcali efetivo residual pode levar a um melhor desempenho dessa madeira.

Pequenas diferenças foram encontradas no $\mathrm{pH}$ dos licores finais dos cozimentos de 1-4 $(13,1 \mathrm{a} 13,4)$. Apenas o cozimento 5 apresentou um menor valor de $\mathrm{pH}$ do licor $(12,4)$, possibilitando alguma precipitação de lignina. Valores de $\mathrm{pH}$ do licor acima de 12,5 são favoráveis à não precipitação de lignina ao final dos cozimentos (LONGUE JÚNIOR, et al., 2009).

\section{Conclusões}

Em relação às madeiras comerciais de Eucalyptus melhoradas geneticamente para produção de celulose, a composição físico-química da madeira Pterogyne nitens apresenta, principalmente, diferenças quanto ao teor de celulose (menor), teor de extrativos (maior), relação S:G da lignina (baixa) e densidade básica (maior), não sendo considerada uma alternativa vantajosa para produção de polpa celulósica.

$\mathrm{Na}$ tentativa de cozimentos dessa madeira para produção de polpa celulósica observouse, em comparação a uma madeira de eucalipto (mesmo Número Kappa 18 e sulfidez), um maior consumo de álcali efetivo, menor rendimento depurado e menor viscosidade. 
Apesar de seu baixo potencial para ser utilizada na produção de polpa celulósica, a madeira apresenta algumas características desejáveis para ser utilizada na produção de energia (carvão vegetal), sendo necessários outros estudos dessa espécie para este e demais usos.

\section{Agradecimentos}

Ao laboratório de Celulose e Papel (LCP-UFV) da Universidade Federal de Viçosa e à Universidade Estadual do Sudoeste da Bahia, pela oportunidade e auxílio.

\section{Referências}

ABNT - ASSOCIAÇÃO BRASILEIRA DE NORMAS TÉCNICAS. NBR 11941: determinação da densidade básica. Rio de Janeiro, 2003. 6p.

ANDO, S. The Antifoams for Pulp and Paper Industry - Defoaming Technology in the Pulp and Paper Industry. Japan Tappi Journal, Tokyo, v. 53, n. 9, p. 1126-1132. 1999.

BARBOSA, L. C. A. et al. Determinação da relação Siringila/Guaiacila da lignina em madeiras de eucalipto por pirólise acoplada à cromatografia gasosa e espectrometria de massas (PI-CG/EM). Química Nova, São Paulo, v. 31, n. 8, p. 2035- 2041. 2008.

CostA, M. M.; MOUTEER, A. H.; COLODETTE, J. L. Ácidos hexenurônicos Parte I: origem, quantificação, reatividade e comportamento durante a polpação kraft. O Papel, São Paulo, v. 62, n. 5, p. 75-85. 2001.

FENGEL, D.; WEGENER, G. Wood, chemistry, ultrastructure, reactions. New York: Walter de Gruyter, 1984. 613p.

FERREIRA, C. R. et al. Avaliação tecnológica de clones de eucalipto: parte 1- qualidade da madeira para a produção de celulose Kraft. Scientia Forestalis, Piracicaba, n. 70, p. 161-170, abr. 2006.

FRAGA, M. P.; BARRETO, P. A. B.; de PAULA, A. Estimação de volume de Pterogyne nitens em plantio puro no sudoeste da Bahia. Pesquisa Florestal Brasileira, Colombo, v. 34, n. 79, p. 2072015, 2014.

GOMES, F. J. B. et al. Influência do teor e da relação $S / G$ da lignina da madeira no desempenho da polpação Kraft. O Papel, São Paulo, v. 69, n. 12, p. 95-105, dez. 2008.

GOMIDE, J. L.; COLODETTE, J. L. Qualidade da madeira. In: BOREM, A. Biotecnologia Florestal. Viçosa: Universidade Federal de Viçosa, 2007. p. 25-54.

GOMIDE, J. L. et al. Caracterização tecnológica, para produção de celulose, da nova geração de clones de Eucalyptus do Brasil. Revista Árvore, Viçosa, v. 29, n. 1, p. 129-137, 2005.

GOMIDE, J. L.; FANTUZZI NETO, H.; REGAZZI, A. J. Análise de critérios de qualidade da madeira de eucalipto para produção de celulose Kraft. Revista Árvore, Viçosa, v. 34, n. 2, p. 339$344,2010$.

GOMIDE, J. L.; FANTUZZI NETO, H. Aspectos fundamentais da polpação kraft de madeira de Eucalyptus. O Papel, São Paulo, v.3 n. 61, p. 62-68, 2000.

GONÇALVES, C. A.; LELIS, R. C. C.; ABREU, H. S. Caracterização físico-química da madeira de sabiá (Mimosa caesalpiniaefolia Benth.). Revista Caatinga, Mossoró, v. 23, n. 1, p. 54-62, jan./ mar. 2010.

GONÇALVES, A. R.; MARTINS, R. C. C.; MARTINS, I. S. Soil seed bank from the understory of Pinus and Eucalyptus in the flona de Brasilia, Brazil. Cerne, Lavras, v. 14, n. 1, p. 23-32, 2008.

GRACE, T. M.; LEOPOLD, B.; MALCON, E. W. Pulp and paper manufacture - Alkaline pulping. Atlanta: Tappi, 1989. 637 p. 
INDÚSTRIA BRASILEIRA DE ÁRVORES. IBÁ 2017. Brasília, 2017. 80 p.

KIMO, J. W. Aspectos químicos da madeira de Eucalyptus grandis W. Hill ex Maiden, visando a produção de polpa celulósica. 1986. 45 p. Dissertação (Mestrado em Ciências Florestais) Universidade Federal de Viçosa, Viçosa. 1986.

LIN, S. Y.; DENCE, C. W. Methods in lignin chemistry. Berlin: Springer-Verlag, 1992. 578 p.

LONGUE JUNIOR, D.; COLODETTE, J. L.; GOMES, F. J. B.; ANDRADE, M., F. Efeito dos sólidos dissolvidos da madeira no desempenho do processo kraft. Scientia Forestalis, Piracicaba, v. 37, n. 84, p405-413, 2009.

LORENZI, H. Árvores brasileiras: Manual de identificação e cultivo de plantas arbóreas nativas do Brasil. Nova Odessa: Plantarum, 1992. 384p.

MANFREDI, M.; OLIVEIRA, R. C.; SILVA, J. C.; REYES, R. I. Q. Ultrasonic treatment of secondary fibers to improve paper properties. Nordic Pulp \& Paper Research Journal, Sundsvall, v. 28 , p. 297, 2013.

MATA, R. A. Efeitos do lixiviado de cinzas de precipitadores eletrostáticos de caldeiras de recuperação no tratamento biológico de efluentes de indústrias de polpa celulósica kraft. 2016. 74 p. Dissertação (Mestrado em Engenharia Civil) - Universidade Federal de Viçosa, Viçosa. 2016.

MOKFIENSKI, A. Importância relativa da densidade básica e da constituição química de madeira de Eucalyptus spp. no rendimento, branqueabilidade e qualidade da polpa kraft. 2004, 153 p. Tese (Doutorado em Ciência Florestal) - Universidade Federal de Viçosa, Viçosa. 2004.

NÓBREGA, A. M. F. et al. Seed bank of natural forest remainder and reforestation areas in a Mogi Guaçu river floodplain, Luiz Antonio country, São Paulo state, Brazil. Revista Árvore, Viçosa, v. 33, p. 403-411, 2009.

REIS, C. A. F. et al. Estratégias na seleção simultânea de vários caracteres no melhoramento do Eucalyptus. Ciência Florestal, Santa Maria, v. 25, n. 2, p. 457-467, 2015.

SCAN - SCANDINAVIAN PULP, PAPER AND BOARDTESTING COMMITTEE. SCAN Test Methods. Estolcolmo: SCAN, 2009. 6p.

SCOTT, R. W. Colorimetric determination of hexuronic acids in plant materials. Analytical Chemistry, Washington, v. 51, n. 7, p 936-941, jun. 1979.

SILVA, L. B.; SANTOS, F. A. R.; GASSON, P.; CUTLER, D. Anatomia e densidade básica da madeira de Caesalpinia pyramidalis Tul. (Fabaceae), espécie endêmica da Caatinga do Nordeste do Brasil. Acta Botanica Brasilica, Belo Horizonte, v. 23, n. 2, p. 436-445. 2009.

SJÖSTRÖM, E. Wood chemistry, fundamentals and applications. New York: Academic Press, 1993. $293 \mathrm{p}$.

SOLAR, R.; KACIK, F.; MELCER, I. Simple Semi-micro Method for the Determination of O-Acetyl Groups in Wood and Related Materials. Nordic Pulp and Paper Research Journal, Sundsvall, v. 2, n. 4, p 139-141.1987.

TAPPI - TECHINICAL ASSOCIATION OF THE PULP AND PAPER INDUSTRY. Tappi Standard Methods, Atlanta: TAPPI Press, 1985, 1993, 1994, 1997, 1999, 2002 e 2007.

VIDAURRE, G. B. Caracterização anatômica, química e físico-mecânica da madeira de paricá (Schizolobium amazonicum) para produção de energia e polpa celulósica. 2010.88 p. Tese (Doutorado em Ciência Florestal) - Universidade Federal de Viçosa, Viçosa. 2010.

ZIECH, R. Q. S. Características tecnológicas da madeira de cedro australiano (Toona ciliata M. Roem) produzida no sul do estado de Minas Gerais. 2008. 106 p. Dissertação (Mestrado em Ciência e Tecnologia da Madeira) - Universidade Federal de Lavras, Lavras. 2008. 